GA-C23380

\title{
FINAL REPORT FOR THE \\ DIII-D RADIATIVE DIVERTOR PROJECT
}

\author{
by \\ R.C. O'NEILL AND R.D. STAMBAUGH
}

Prepared under

Contract No. DE-AC03-99ER54463

for the U.S. Department of Energy

JUNE 2003 


\section{DISCLAIMER}

This report was prepared as an account of work sponsored by an agency of the United States Government. Neither the United States Government nor any agency thereof, nor any of their employees, makes any warranty, express or implied, or assumes any legal liability or responsibility for the accuracy, completeness, or usefulness of any information, apparatus, produce, or process disclosed, or represents that its use would not infringe privately owned rights. Reference herein to any specific commercial product, process, or service by trade name, trademark, manufacturer, or otherwise, does not necessarily constitute or imply its endorsement, recommendation, or favoring by the United States Government or any agency thereof. The views and opinions of authors expressed herein do not necessarily state or reflect those of the United States Government or any agency thereof. 
GA-C23380

\title{
FINAL REPORT FOR THE DIII-D RADIATIVE DIVERTOR PROJECT
}

\author{
by \\ R.C. O'NEILL AND R.D. STAMBAUGH
}

Prepared under

Contract No. DE-AC03-99ER54463

for the U.S. Department of Energy 
R.C. O'Neill

FINAL REPORT FOR THE DIII-D RADIATIVE DIVERTER PROJECT

APPROVALS

Approved: $\frac{R \cdot \Delta \cdot \text {. Stambrang }}{\text { R.D. Stambaugh }}$ DIII-D Program Director General Atomics

Re w Callus

R.W. Calls

Director Fusion Technology \& Projects General Atomics

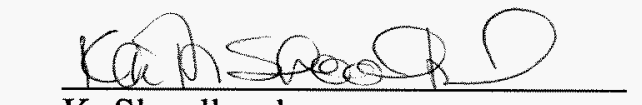

K. Shoolbred

Director, Program Support General Atomics

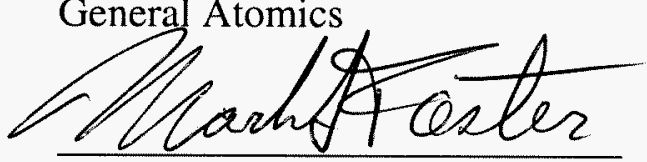

M.S. Foster

Onsite Technical Representative Berkeley Site Office DOE/OAK

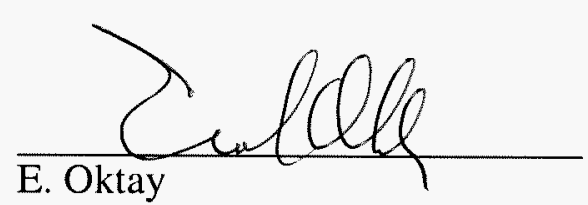

DIII-D Program Manager DOE Office of Fusion Energy Science

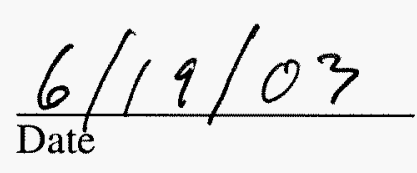

$\frac{6 / 19 / 03}{\text { Date }}$

$6 / 19103$

Date

$\frac{6 / 23 / 03}{\text { Date }}$

$8 / 5 / 03$

Date

GENERAL ATOMICS REPORT GA-C23380 i 


\section{CONTENTS}

APPROVALS $\ldots \ldots \ldots \ldots \ldots \ldots \ldots \ldots \ldots \ldots \ldots \ldots \ldots \ldots \ldots \ldots \ldots \ldots \ldots \ldots \ldots$

BACKGROUND AND HISTORY, PROJECT EVOLUTION $\ldots \ldots \ldots \ldots \ldots \ldots$

DIII-D Five Year Plan for $1994-1998 \ldots \ldots \ldots \ldots \ldots \ldots \ldots \ldots \ldots \ldots$

Radiative Divertor Project Review - June 14-15, 1994 . . . . . . . . . . . 1

Management Plan for the DIII-D Radiative Divertor Project - October 1, 1994

Authorizing Letter - November $17,1994 \ldots \ldots \ldots \ldots \ldots \ldots \ldots \ldots$

Diagnostic Plan for the Radiative Divertor — January, $1995 \ldots \ldots \ldots \ldots \ldots . \ldots$

Plan for the Use of Vanadium in the RDP, March 22, $1995 \ldots \ldots \ldots \ldots \ldots \ldots$

Management Plan for the Radiative Divertor Project, Revision 1, July 22, 1996

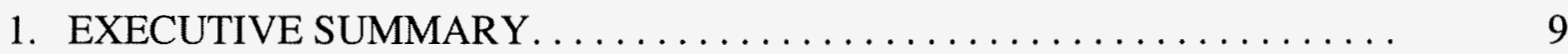

2. PROJECT SCOPE AND OBJECTIVES $\ldots \ldots \ldots \ldots \ldots \ldots \ldots \ldots \ldots \ldots$

2.1. Overall Project Management $\ldots \ldots \ldots \ldots \ldots \ldots \ldots \ldots \ldots \ldots \ldots \ldots \ldots$

2.2. Technical Description of RDP . . . . . . . . . . . . . 12

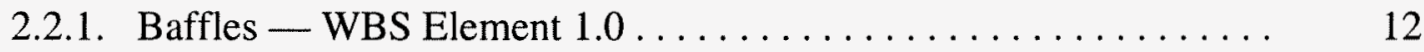

2.2.2. In-Vessel Cryosystems (Divertor Cryopumps) — WBS Element $2.0 \quad 14$

2.2.3. Ex-Vessel Support Systems - WBS Element $3.0 \ldots \ldots \ldots \ldots \ldots .14$

2.2.4. Diagnostic Integration/Property Management — WBS Element 4.0 . 15

2.3. Cost Baseline ............................... 15

2.4. Schedule Baseline. . . . . . . . . . . . . . . . . . . . . 15

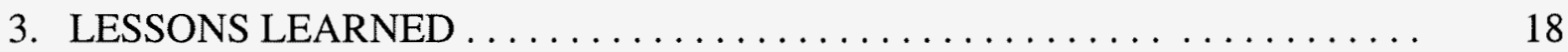

REFERENCES .................................. 19 


\section{LIST OF FIGURES}

1. Features of the DIII-D Radiative Divertor Design $\ldots \ldots \ldots \ldots \ldots \ldots \ldots$

2. DIIID Divertor Development Plan $\quad \ldots \ldots \ldots \ldots \ldots \ldots \ldots \ldots \ldots$

3. Modular radiative divertor hardware provides flexibility $\ldots \ldots \ldots \ldots \ldots$

4. DIII-D Divertor Configuration Planned, Phase 1A in 1997 and

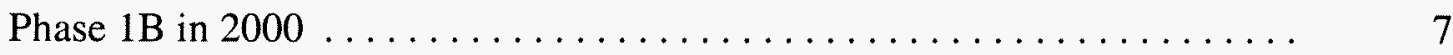

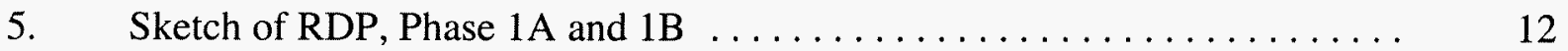

6. Radiative divertor schedule $\ldots \ldots \ldots \ldots \ldots \ldots \ldots \ldots \ldots \ldots \ldots \ldots$

\section{LIST OF TABLES}

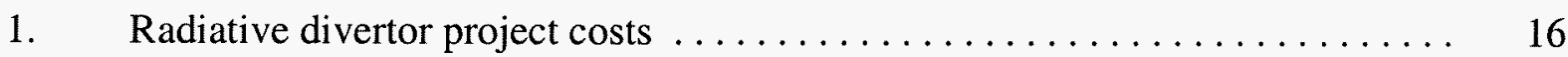




\section{BACKGROUND AND HISTORY, PROJECT EVOLUTION}

\section{DIII-D FIVE YEAR PLAN FOR 1994-1998}

The Radiative Divertor Project originated in 1993 when the DIII-D Five Year Plan for the period 1994-1998 was prepared. The Project Information Sheet described the objective of the project as "to demonstrate dispersal of divertor power by a factor of ten with sufficient diagnostics and modeling to extend the results to ITER and TPX." Key divertor components identified were:

1. Carbon-carbon and graphite armor tiles

2. The divertor structure providing a gas baffle and cooling

3. The divertor cryopumps to pump fuel and impurities.

A conceptual design target was set for February, 1994. The Project was envisioned to take place in the years 1994-1996 with the following expenditure profile for each year.

$\begin{array}{cccc}\text { Cost Summary }(\$ 000) \\ \text { FY94 } & \underline{\text { FY95 }} & \underline{\text { FY96 }} & \text { Total } \\ 3,360 & 8,796 & 3,919 & 16,075\end{array}$

\section{RADIATIVE DIVERTOR PROJECT REVIEW - JUNE 15-16, 1994}

The Department of Energy convened a formal review of the proposed Radiative Divertor Project at General Atomics, June 15-16, 1994. Presentations at that review were:

Opening Remarks

DIII-D Program Overview

Overview of the Radiative Divertor Program

Divertor Requirments for the AT Program

Modeling Applied to the RDP

Physics Review of Biasing

Engineering Conceptual Design

Management Plan: Cost and Schedule

Diagnostics and Physics Measurements
R.D. Stambaugh

T.C. Simonen

S.L. Allen (LLNL)

T.S. Taylor

G.D. Porter (LLNL)

G.M. Staebler (GA)

J.P. Smith (GA)

J.P. Smith/S.L. Allen

D.N. Hill (LLNL)

The divertor configuration presented (Fig. 1) was a double-null divertor with a short but reasonably baffled design to be relevant to the ITER slot divertor. Cryopumps were provided to 
separately pump both the inner and outer strikepoints of both ends of the double null. The lower, outer pump was a carry-over from a previous installation.

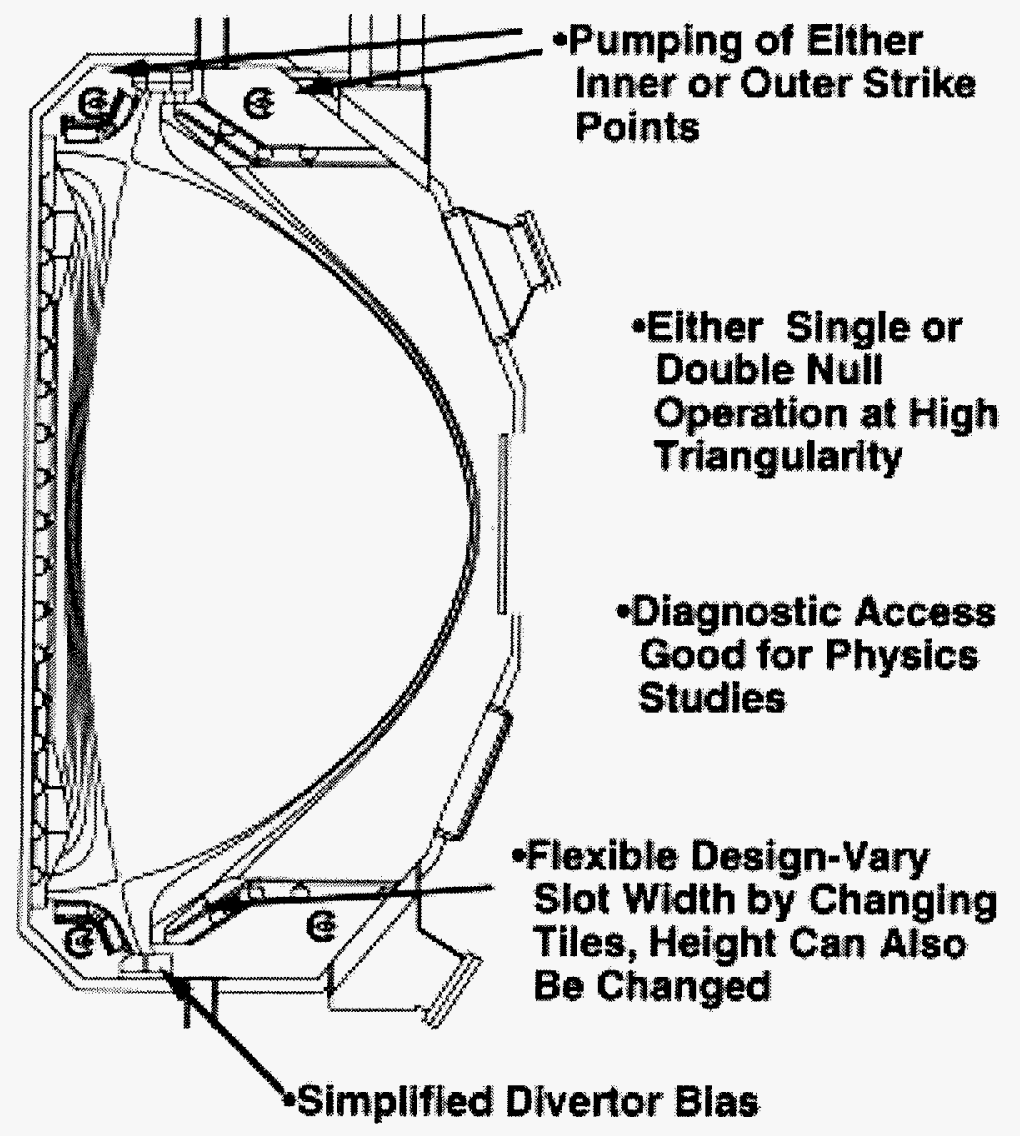

Fig. 1. Features of the DIII-D Radiative Divertor Design.

This divertor was needed by the DIII-D Advanced Tokamak Program for density and impurity control and power dispersal for long pulse operation. The design supported the then current TPX project since it was of a similar shape and for a similar mission within the project. This design was also intended to test physics features of the ITER divertor design and to allow geometry variations (divertor slot length and width). The proposed program would address issues that were unlikely to be resolved anywhere in the world except in DIII-D:

1. Double versus single null

2. The necessity of pumping the inner leg

3. Variation of slot length

4. Variation of slot width

5. Divertor biasing effects. 
The overall Divertor Development Plan for DIII-D is shown in Fig. 2. The design requirements were:

1. Provide power exhaust for $38 \mathrm{MW}$ for 10 seconds

2. Use proven existing technology - ADP biasing, ADP baffle, ADP cryopump, first wall and divertor armor.

3. Maintain conditioning capabilities - vent recovery time of 1-3 weeks and use of the then current inductive baking system.

4. Satisfy the intent of the ASME code.

Important changes had been made in the Project concept since the 1993 description. The Project was now separated into a Phase I and a Phase II. Phase I included the first construction and operation of the $23 \mathrm{~cm}$ slot divertor as shown in Fig. 3, providing high triangularity, double-null operation with cryopumping of all strike points. Phase II covered various future options such as variations in slot length (33 and $43 \mathrm{~cm}$, Fig. 3), unipolar biasing, the gas bag divertor, and long pulse operation.

The total cost of Phase I was $\$ 9.5 \mathrm{M}$ and the total cost of Phase II was $\$ 6.6 \mathrm{M}$ for an overall total of $\$ 16.1 \mathrm{M}$. While the total cost was kept in the same envelope as in the 1993 planning, the configuration of the project had changed considerably to provide more physics investigation flexibility in the new Phase II. To hold the Project cost, careful analysis had shown that expensive carbon-carbon composite materials could be deleted in favor of much more economical graphite tiles. The cost layout over years was:

\section{RDP Upgrade Costs}

\begin{tabular}{|c|c|c|c|c|}
\hline Costs $(\$ M)$ & FY95 & FY96 & FY97 & FY97-01 \\
\hline Phase I & 2.9 & 5.0 & 1.6 & \\
\hline Phase II & & & & 6.6 \\
\hline
\end{tabular}

The Review Committee strongly endorsed proceeding with the Plan as outlined.

\section{MANAGEMENT PLAN FOR THE DIII-D RADIATIVE DIVERTOR PROJECT — OCTOBER 1, 1994}

After the successful review, a Project Management Plan was issued in October, 1994. Refined cost estimates and engineering innovations had reduced the overall Project cost to $\$ 14.6 \mathrm{M}$, with Phase I at $\$ 8.7 \mathrm{M}$ and Phase II at $\$ 5.9 \mathrm{M}$. This plan identified General Atomics as having lead responsibility for the design and engineering of the Radiative Divertor Project. Lawrence Livermore National Laboratory had the senior management responsibility for the Radiative Divertor 


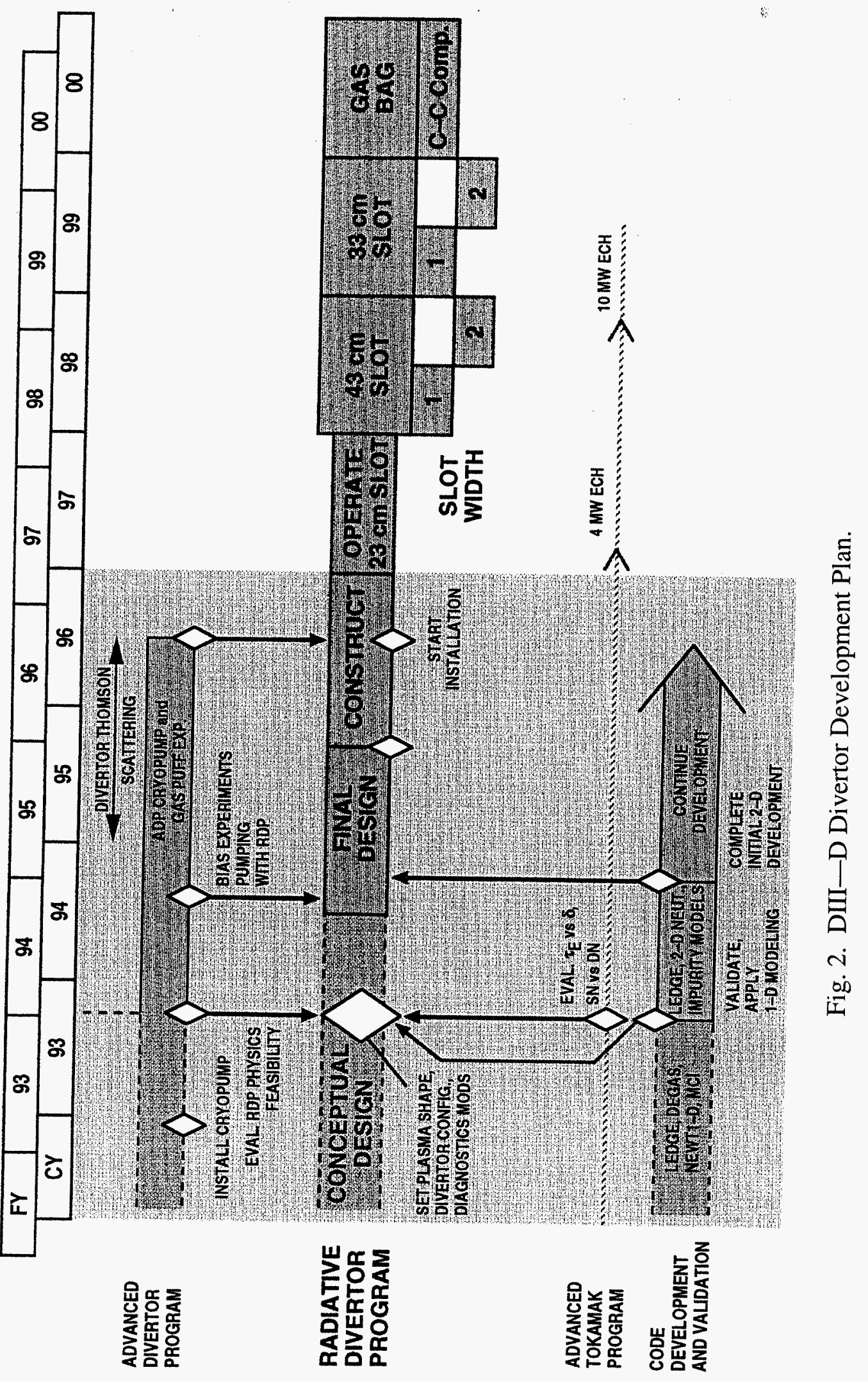




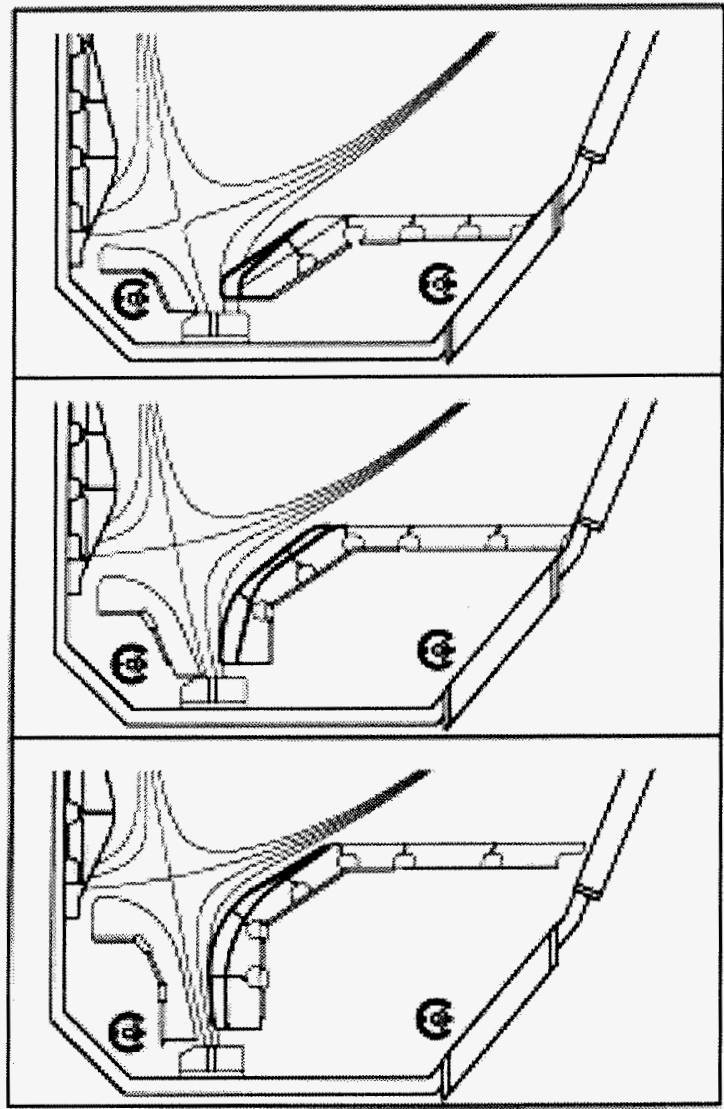

\section{$23 \mathrm{~cm}$ slot \\ Fleld Line \\ Length $=11 \mathrm{~m}$}

$33 \mathrm{~cm}$ slot

Field Line

Length $=12.75 \mathrm{~m}$

$43 \mathrm{~cm}$ slot

Field Line

Length $=13.25 \mathrm{~m}$

Fig. 3. Modular radiative divertor hardware provides flexibility.

Project and the lead in divertor physics and modeling. Divertor diagnostics would involve contributions from GA, LLNL, ORNL, UCSD, UCLA, and Sandia National Laboratory.

\section{AUTHORIZING LETTER - NOVEMBER 17, 1994}

On November 17, the RDP Project was authorized by a letter from Erol Oktay, Group Leader, Base and Advanced Toroidal Program, Division of Confinement Systems, Office of Fusion Energy, Office of Energy Research to Tom Simonen, DIII-D Program Director. This letter gave formal approval to Phase I with an estimated total cost of $\$ 8.7 \mathrm{M}$ and a funding profile of $\$ 2.7 \mathrm{M}$ in FY1995, \$4.6M in FY1996, and \$1.4M in FY1997. The Project start date was October 1994 and the end date was December 1996. The diagnostics were not included in the Project budget.

\section{DIAGNOSTIC PLAN FOR THE RADIATIVE DIVERTOR - JANUARY, 1995}

A Diagnostic Plan for the Radiative Divertor was created in January, 1995. This multiinstitutional work was to be funded from Research Operations budgets. 


\section{PLAN FOR THE USE OF VANADIUM IN THE RDP, MARCH 22, 1995}

In order for the Fusion Program generally to begin making progress in serious use of low activation material in fusion systems, General Atomics proposed in 1995 to fabricate the upper half of the Radiative Divertor out of a low activation alloy of Vanadium (V-4Cr-4Ti). The Plan for Use of Vanadium Alloys in the Radiative Divertor, was created as Appendix B to the Management Plan for the DIII-D Radiative Divertor Project. A cost of $\$ 1.396 \mathrm{M}$ was identified for procuring the Vanadium material and using it in the RDP fabrication. These costs were not incorporated in the RDP Project; they were to be born by the DIII-D RO budget and the technology program budgets of GA's partners in this effort, ANL and ORNL.

In this effort, GA procured the largest heat $(800 \mathrm{~kg})$ of the low activation alloy $\mathrm{V}-4 \mathrm{Cr}-4 \mathrm{Ti}$ which has ever been made. Small samples tests were made in DIII-D and in later years in the JFT-2M tokamak in Japan. Test plates were made for the lower divertor region of DIII-D and exposed in the DIII-D plasma chamber. Funding limitations on the RO budget starting in 1996 caused a descoping of the ambitions of this effort to first just installing the upper private flux baffle made of Vanadium and finally to a cancellation of the entire Vanadium effort.

\section{MANAGEMENT PLAN FOR THE RADIATIVE DIVERTOR PROJECT, REVISION 1, JULY 22, 1996}

FY96 saw a very large reduction in the overall budget of the Fusion Energy Sciences Program nationally. The DIII-D Program saw a $\$ 12 \mathrm{M}$ reduction, about $25 \%$. This severe reduction necessitated reexamination of all expenditures and projects in the DIII-D Program.

For the Radiative Divertor Program, the necessary changes were captured in Revision One of the Management Plan, July 22, 1996. The cancellation of the TPX Project removed that motivating element for the RDP. Faced with necessary Project descoping, the decision was made to only install the upper half of the RDP. Extensive physics assessements led to the conclusion that it would be desirable for DIII-D to spend some years with the flexibility to study a highly baffled divertor in the upper half and to compare that operation with the open divertor in the lower half. Also, an extensive investment had been made in the diagnostic set for the lower divertor, including a novel Thomson scattering system that could make unique 2-D maps of the divertor plasma by sweeping the divertor in the open lower divertor geometry. These diagnostic capabilities would have been severely compromised by the highly baffled lower divertor geometry proposed in the RDP. The Phase I effort, the only part of the RDP that had been approved, was rebaselined to $\$ 8.1 \mathrm{M}$.

Reviews of the Project were completed by the Fusion Energy Advisory Panel (FEAC, now FESAC) in December 95, by the DIII-D Executive Committee in January 96, and by the Facilities Subpanel of FEAC in March of 1996. In the course of all these reviews, the Project was revised and a staged installation was developed. Specifically, the Phase I installation was broken into two parts, Phase IA and Phase IB. Phase IA was just the upper outer baffle and cryopump. Phase IB was the 
inner private flux baffle and cryopump. Completion of Phase IB would be equivalent to the original Phase I. These phases are shown in Fig. 4.

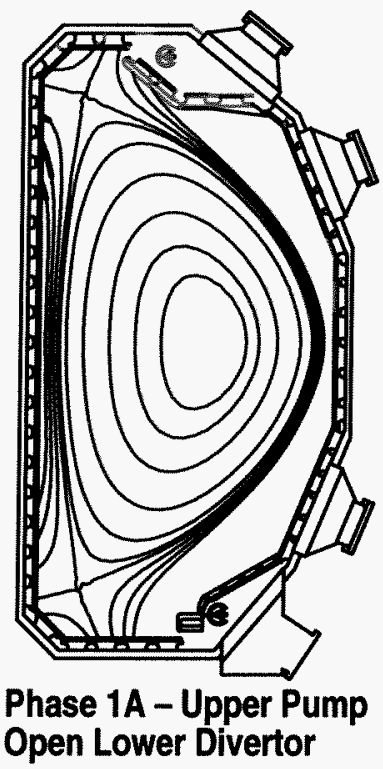

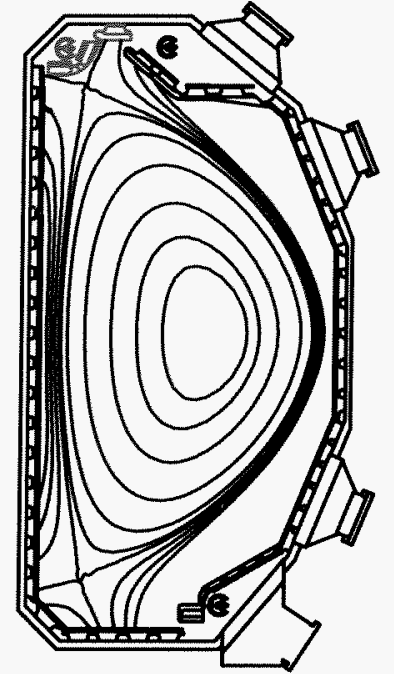

Phase 1B - Inner Pump \& Baffle Open Lower Divertor

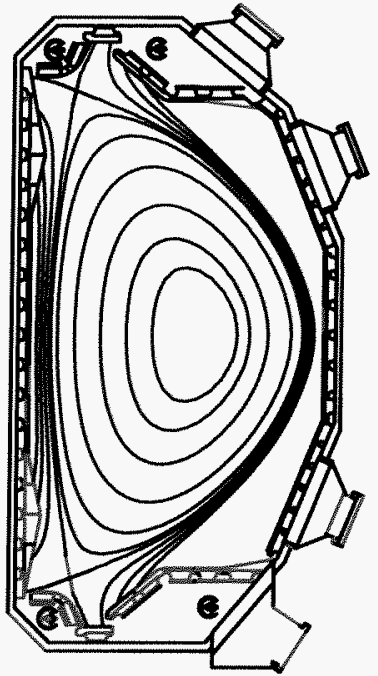

Full RDP Installation Pumped AT DN Shape

Fig. 4. DIII-D Divertor Configurations Planned. Phase 1A in 1997 and Phase IB in 2000.

Phase 1B was to include construction of the upper inner private flux baffle out of Vanadium. A separate management plan was written for that. But as discussed above, this Vanadium plan was eventually discarded for cost reasons.

Phase 1A was scheduled for completion December 31, 1996 and Phase 1B December 31, 1998. The cost of Phase $1 \mathrm{~A}$ was to be $\$ 4.168 \mathrm{M}$ and for Phase $1 \mathrm{~B} \$ 3.924 \mathrm{M}$ for a Project total cost of $\$ 8.091 \mathrm{M}$. Phases $1 \mathrm{~A}$ and $1 \mathrm{~B}$ are now complete and the remainder of this report concerns the details of those installations.

The July 22, 1996 Management Plan budgets are in Table I up to 1999. For 1999 that plan envisioned $\$ 804 \mathrm{~K}$ to reach a total of $\$ 8091 \mathrm{~K}$. In April 1999, looking toward project completion, a further revision of the Management Plan was made. The total of those estimates for 1999 and 2000 plus actuals for 1998 and prior years was $\$ 7215 \mathrm{~K}$. The final project cost of $\$ 7223 \mathrm{~K}$ hit that target within $0.1 \%$. 


\section{EXECUTIVE SUMMARY}

The radiative divertor is a major element of the DIII-D program. The divertors were designed to provide particle control for highly triangular advanced tokamak operations. In the divertors, the power and particles are exhausted over a very narrow spatial region, resulting in very high power and particle fluxes per unit area. The challenge has been to simultaneously control the heat and particle flow and to minimize the adverse influence on the core plasma. High heat fluxes can be handled with thin materials but divertor materials erode quickly in the presence of energetic particle fluxes. Erosion can be minimized with thick materials or the use of high- $Z$ materials, but it is difficult to transport the heat through thick structures and high- $Z$ materials may induce plasma impurities.

The major goals of the divertor project have been to simultaneously control the heat and particle fluxes so that "conventional" (and ultimately low activation) materials can be used. In addition, the divertor must provide some control of particle and impurity content of the core plasma. The design for the DIII-D divertors addresses these issues in an advanced tokamak (i.e., double-null plasma with high triangularity plasma shape). The design has included the basic ingredients of an efficient and effective divertor, and further research is aimed at demonstrating: simultaneous heat flux control, erosion control, and core particle and impurity (including $\mathrm{He}$ or $\alpha$-particle) control.

The RDP or upper radiative divertor upgrade was divided into two phases. The first, Phase 1A, was to design, install, and operate a divertor and cryopump in the upper outer radius of DIII-D (Fig. 4). Installation of the Phase 1A divertor and cryopump was completed in January 1997 and the system has been operational since. The second phase, Phase 1B, was to design, install, and operate a divertor and cryopump in the upper inner radius of DIII-D. The physical installation of the pump and divertor was completed in December 1999. Operation of the pump commenced in January of 2000 .

The total cost of the RDP was $\$ 7,223 \mathrm{~K}$, a cost reduction of $\$ 1,500 \mathrm{~K}$ relative to the original 1994 plan. With the 25\% reduction in DIII-D funding in FY96 it was necessary to re-plan the RDP budget, schedule, and scope relative to the October $1,1994, \$ 8,723 \mathrm{~K}$ plan. A $\$ 8,091 \mathrm{~K}, 1996$ plan developed cost savings by simplifications in the engineering design of the baffle structure [1] and eliminating the modification of the lower divertor (maintaining excellent diagnostic access for divertor physics research but giving up close baffling of high-triangularity advanced tokamak shaped double-null plasmas). That original three-year project was divided into two three-year phases. A 1999 plan [2] identified further cost savings, among them, eliminating a second external cryostat. (Tests had shown one cryostat could supply enough helium flow for both upper cryopumps.)

The RDP was a collaborative effort between General Atomics (GA) and several collaborators. While GA led the design and engineering of the RDP, each party participated as a team in all 
phases of the project. Moreover, the project depended heavily on significant contributions from several collaborators, particularly in the area of new diagnostics, diagnostic modifications, and modeling. Lawrence Livermore had the diagnostic program management responsibility for the RDP. 


\section{PROJECT SCOPE AND OBJECTIVES}

The objective of both phases of the RDP (Phases 1A and 1B) was to design, fabricate, assemble, and install divertors and cryopumps in the upper quadrants of the DIII-D vacuum vessel. The systems were to be operational by February 2000 with a cost of $\$ 7.2$ million. The purpose of the divertor(s) was to implement and investigate the following:

- Reduce divertor heat flux by a localized radiation source $(\sim 10 \mathrm{~cm}$, with a halo region for neon).

- $\quad$ Reduce the plasma pressure along the separatrix, with an increase away from the separatrix.

- Provide density control, helium exhaust, and impurity control by a more-closed divertor geometry and active pumping. This geometry is consistent with advanced tokamak (high plasma triangularity) operation.

- Reduce the divertor heat flux with less influence on the core plasma, (i.e., reduce the density rise with a more closed slot divertor configuration).

- Evaluate the effect of the divertor geometry on the divertor and plasma performance. We are implementing a very flexible design in which we can readily change the slot width and slot height.

The work breakdown structure was defined in the Management Plans for the DIII-D Radiative Divertor Project (GA-C23340), which defined the technical, cost, and schedule requirements necessary to achieve the program objectives. GA established within its own project organization, a system for controlling and accomplishing the work segments.

\subsection{OVERALL PROGRAM MANAGEMENT}

The technical, cost, and schedule baselines were the basis for control of the DIII-D Radiative Divertor Project. GA utilized a system of reducing the baselines down to identifiable subtasks and developing an Approved Task Authorization for each subtask, with an appointed subtask manager held responsible for cost and schedule control. A monthly assessment of the progress of each subtask was held and a project cost-to-complete re-estimate was performed every six months. 


\subsection{TECHNICAL DESCRIPTION OF RDP}

The overall sketch of the RDP, Phase 1A and 1B is shown in Fig. 5 with its major components.

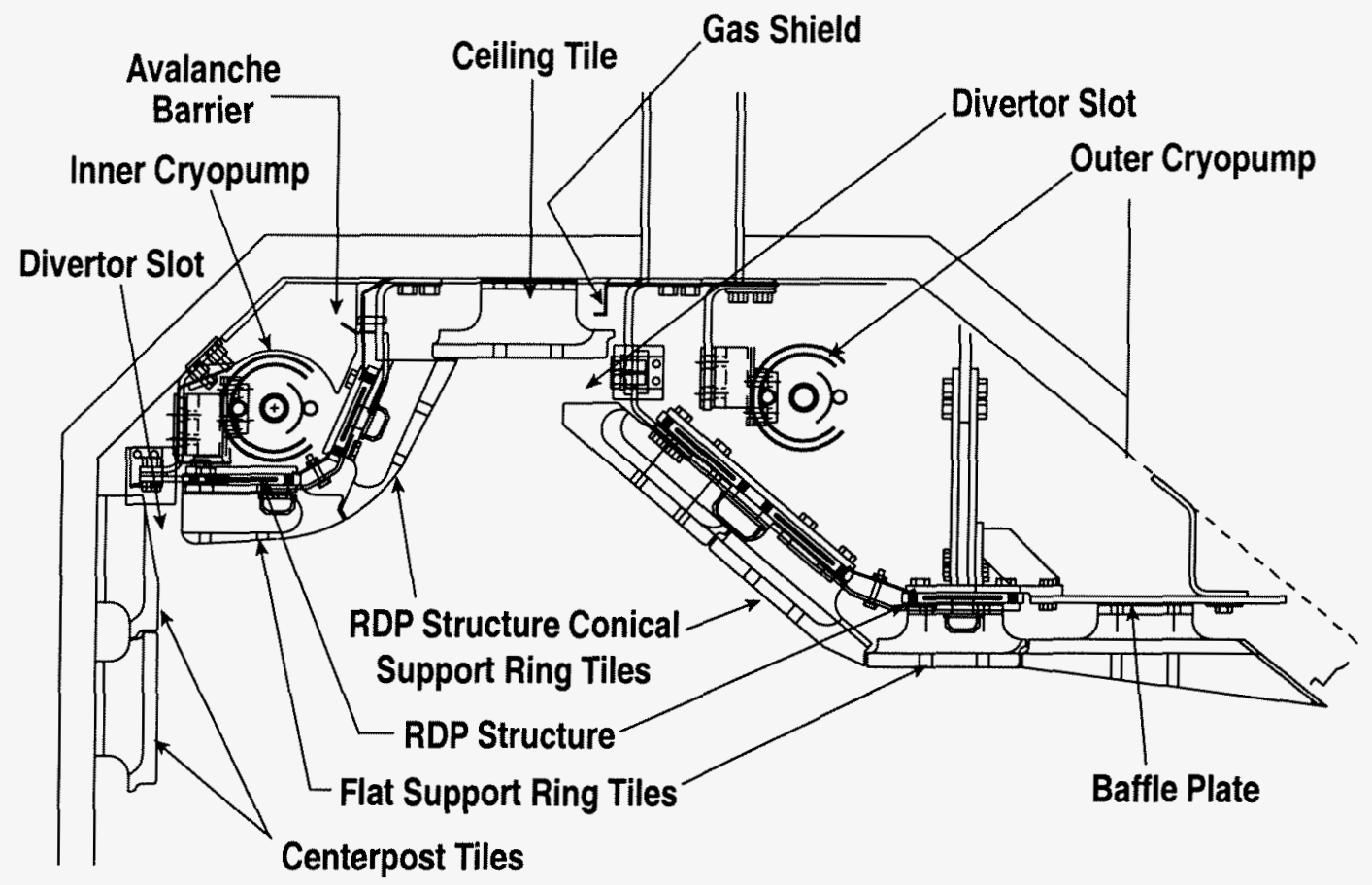

Fig. 5. Sketch of RDP, Phase $1 \mathrm{~A}$ and $1 \mathrm{~B}$.

\subsubsection{Baffles - WBS Element 1.0}

This element was comprised of the design, fabrication, and installation of the two upper baffles. The baffles are the major divertor slot structures and consist of graphite tiles mounted on the conical and flat support rings. The rings are water-cooled in the areas near the slot, keeping the structure at a constant starting temperature with a ten minute DIII-D plasma repetition rate. The structure was designed to be flexible so that the height of the slot can be varied from an X-point to target plate distance of $23 \mathrm{~cm}$ up to $43 \mathrm{~cm}$.

To facilitate tracking of the components and assembly for this portion of the project, two WBS sub-elements were instituted: 1.1 (structure) and 1.2 (tiles and hold-down hardware). Element 1.1 included the design, fabrication, assembly, and installation of the water-cooled rings, supports, feedlines, and feedthroughs. Element 1.2 contained the design, fabrication, cleaning, and installation of the graphite tiles and hold-down hardware. In Phase 1A, the budget for Elements 1.1 and 1.2 was exceeded slightly $(\$ 2,308 \mathrm{~K}$ actual costs versus $\$ 2,300 \mathrm{~K}$ budgeted, see Table 1$)$. Though this is small for the budget of the phase overall, it should be noted in FY97, the budget was over run by $\$ 307 \mathrm{~K}$. This occurred for two reasons. The first was failure of the manufacturer of the cooling 
rings to complete the machining of the rings. The manufacturer machined only half of the rings prior to dropping the job. This required GA to bring the job in-house and complete machining with labor and materials that were not budgeted. The second reason for the over run was the development of information on halo currents and loads created by them. The new information required significant engineering analysis to verify the structure could handle the load. The lessons learned from these two problems were carried forward into Phase $1 \mathrm{~B}$ of Element 1.0 which permitted the successful completion of the installation of upper inner baffle structure and tiles on time.

In Phase 1B, Element 1.0 , the budget was under run $(\$ 1,524 \mathrm{~K}$ actual costs versus $\$ 2,637$ budgeted) but during this phase, the overall scope of the project was changed. Cost savings were realized by simplifications in the engineering design of the baffle structure. The change in scope was reflected in the new Management Plan, revised April 1999, which was written in the later part of this phase.

Also in the later part of this phase, the budgets for the structure, tiles and hardware was over spent. This was due to tasks being added to the project as components and systems were assembled, and further analysis were performed. Analysis in four areas revealed that enhanced pumping and plasma performance could be achieved and further protection of the divertor structure would be prudent. These four areas were: reduction of plasma carbon contamination and improvement of tile performance, increased protection of structures, improved pumping capabilities, and improved tile hold-down nut bars. None of these tasks were included in the original scope of work. The focus of reduction of plasma carbon contamination was to reduce the temperature of critical tile areas. Generally, this meant reducing the surface area of exposed edges in high heat flux regions: rows 1 and 2 on the centerpost, and the tiles on the ceiling. This was accomplished by rounding the plasma facing surfaces (centerpost tiles), reducing the poloidal gaps between adjacent tiles from 0.1 in. to $0.025 \mathrm{in}$., and by contouring the tiles in order to remove any steps. Locally, the tile performance was improved at the Thomson dump location where the dump was removed and replaced by high conductivity carbon composite tiles. Increased structure protection dealt with insuring that the structure was not exposed to plasma field lines for any and all plasma configurations. This led to the addition of protective tile assemblies on the ligaments and inner supports of the inboard baffle. The third area was concerned with increasing the pumping performance. Analysis revealed a leak path through the archway of the ceiling tiles. A seal was designed, fabricated, and installed in order to rectify this problem. The final area involved the tile hold-down nut bars. During previous vents, it was observed that a few tiles had lost some of their pre-load during operations. An investigation was conducted and it was determined that the pre-load system of three belville washers per stud was extremely sensitive to creep in the compliant layer of graphoil (located between the nutbar and tile and the tile and vacuum vessel). A less sensitive configuration of four washers per stud was installed on all new tiles as well as any old tile that was temporarily removed and replaced. 


\subsubsection{In-Vessel Cyrosystems (Divertor Cryopumps) - WBS Element 2.0}

As shown in Fig. 4, there are two additional divertor cryopumps based on the current successful advanced divertor DIII-D design, located in the outer, lower quadrant of DIII-D. The upper cryopumps use the same concept as the advanced divertor cryopump which was installed in the early 1990s.

The DIII-D cryopumps consist of liquid-helium cooled tubes that are thermally shielded by a liquid-nitrogen cooled shell. The pumps are toroidally continuous structures that have been designed to handle the induced disruption loads. This WBS covered the design, fabrication, and installation of the upper cryopumps and feedthroughs. In-house fabrication and assembly was also included in this element. For Element 2.0, Phase 1A, the budget was exceeded by $\$ 12 \mathrm{~K}(\$ 1052 \mathrm{~K}$ actual costs versus $\$ 1044 \mathrm{~K}$ budgeted). This over run was due to manufacturing, welding, and processing the liquid nitrogen shells and tubes, and the liquid helium tubes. The costs of these tasks were simply under estimated during the development of the budget.

For Phase 1B of Element 2.0, the budget was under spent. As stated before, the scope of the overall project was changed and the Management Plan and budget were changed accordingly in the latter part of this phase. In the last year of this phase, FY00, budget was overspent due to the addition of an out-of-scope task. Additional analysis of the proximity of the private flux baffle to the plasma seperatrix, revealed electrons could orbit around the centerpost under the baffle structure which could damage the cryopump, diagnostics or the structure itself. To eliminate this concern, electron avalanche shields were designed, fabricated and installed at $90^{\circ}$ intervals.

\subsubsection{Ex-Vessel Support Systems - WBS Element 3.0}

This element consists of mainly the ex-vessel support systems for the cryopumps. These systems supply the liquid nitrogen and liquid helium to the cryopumps. The upgrade for the system was essentially duplicated from the system that operates the advanced divertor cryopump. A new transfer line was installed to supply liquid nitrogen and helium to both of the upper cryopumps. This new line was spliced into the existing line and system, thus eliminating the need for a new cryostat. Modifications to the liquid helium distribution box were also necessary.

During Phase 1A, the budget for this element was exceeded by $\$ 310 \mathrm{~K}$ ( $\$ 959 \mathrm{~K}$ actual cost versus $\$ 649 \mathrm{~K}$ budgeted). This was due to an error in the July 1996 Management Plan numbers. Due to different options being considered including not completing the installation of the ex-vessel system, approximately $\$ 100 \mathrm{~K}$ of installation was not included in the estimates. The other $\$ 210 \mathrm{~K}$ over run can be attributed to three things: 
1. Budget limitations required stopping and starting some procurement contracts. There were termination fees as well as higher costs when restarted.

2. Added complexity of upper platform design and installation to meet the requirements of all DIII-D users rather than just supporting the cyrostat.

3. Additional labor cost on the assembly and installation of the ex-vessel system.

In Phase $1 \mathrm{~B}$, the budget was significantly under spent $(\$ 304 \mathrm{~K}$ actual cost versus $\$ 1176 \mathrm{~K}$ budgeted). The planned second cryostat was removed from the project scope when tests of the first cryostat showed it could probably handle both upper pumps. Even with the adjustments due to other change of scope of the project, this element proceeded well, meeting the schedule and under running the budget.

\subsubsection{Diagnostic Integration/Project Management - WBS Element 4.0}

This WBS element provided the engineering interface support for diagnostic installation and modification efforts, and overall management of the project. The design, fabrication, and installation of the diagnostics was completed by various collaborating institutions and was not part of this WBS or of the project as a whole. For Phase $1 \mathrm{~A}$ and $1 \mathrm{~B}$, the budgets for this element were over spent by $\$ 28 \mathrm{~K}$ and $\$ 52 \mathrm{~K}$ respectively. In Phase $1 \mathrm{~A}$, the budget was exceeded due to under estimating the labor required to install thermocouples and various probes. For Phase $1 \mathrm{~B}$, the cost of updating/correcting drawings was under estimated.

\subsection{COST BASELINE}

The total cost of the RDP was $\$ 7,223 \mathrm{~K}$. This is a cost reduction of $\$ 1,500 \mathrm{~K}$ relative to the original 1994 plan and an underrun of $\$ 868 \mathrm{~K}$ relative to the Management Team, Revision 1 , dated July 22, 1996. The baseline budget profile for (FY95-FY00) the RDP is shown in Table 1 according to the WBS elements.

\subsection{SCHEDULE BASELINE}

The project schedule is shown in Fig. 6. 
TABLE 1

Radiative Divertor Project Costs (\$K)

\begin{tabular}{|c|c|c|c|c|c|c|c|c|c|c|c|c|c|c|c|}
\hline & \multicolumn{6}{|c|}{ PHASE 1A } & \multicolumn{8}{|c|}{ PHASE 1B } & \multirow{3}{*}{$\begin{array}{l}\text { Total of } \\
\text { Actuals }\end{array}$} \\
\hline & \multicolumn{2}{|c|}{ FY95 } & \multicolumn{2}{|c|}{ FY96 } & \multicolumn{2}{|c|}{ FY97 } & \multicolumn{2}{|c|}{ FY97 } & \multicolumn{2}{|c|}{ FY98 } & \multicolumn{2}{|c|}{ FY99 } & \multicolumn{2}{|c|}{ FYOO } & \\
\hline & Actual & $\begin{array}{l}\text { Mgmt. Plan } \\
\text { Rev. } 1\end{array}$ & Actual & $\begin{array}{l}\text { Mgmt. Plan } \\
\text { Rev. } 1\end{array}$ & Actual & $\begin{array}{l}\text { Mgmt. Plan } \\
\text { Rev. } 1\end{array}$ & Actual & $\begin{array}{c}\text { Mgmt. Plan } \\
\text { Rev. } 1\end{array}$ & Actual & $\begin{array}{l}\text { Mgmt. Plan } \\
\text { Rev. } 1\end{array}$ & Actual & $\begin{array}{l}\text { Mgmt. Plan } \\
\text { Rev. 4/99 }\end{array}$ & Actual & $\begin{array}{c}\text { Mgmt. Plan } \\
\text { Rev. 4/99 }\end{array}$ & \\
\hline 1.0 Baffles & 606 & 616 & 1,095 & 1,384 & 607 & 300 & 157 & 276 & 344 & 1,476 & 863 & 885 & 160 & 0 & 3,832 \\
\hline 1.1 Structure & 557 & 549 & 757 & 927 & 553 & 280 & 157 & 172 & 280 & 1,115 & 464 & 591 & 79 & 0 & \\
\hline 1.2 Tiles and Hardware & 49 & 67 & 338 & 457 & 54 & 20 & 0 & 104 & 64 & 361 & 399 & 294 & 81 & 0 & \\
\hline 2.0 In-Vessel Cryosystems & 430 & 430 & 524 & 513 & 98 & 101 & 31 & 93 & 146 & 476 & 382 & 399 & 34 & 0 & 1,645 \\
\hline 3.0 Ex-Vessel Support & 105 & 105 & 387 & 320 & 467 & 224 & 0 & 99 & 0 & 552 & 214 & 270 & 90 & 255 & 1,263 \\
\hline $\begin{array}{l}\text { 4.0 Diagnostic Integration/Project } \\
\text { Management }\end{array}$ & 71 & 71 & 108 & 104 & 24 & 0 & 43 & 55 & 82 & 92 & 84 & 81 & 71 & 0 & 483 \\
\hline TOTALS & 1,212 & 1,222 & 2,114 & 2,321 & 1,196 & 625 & 231 & 523 & 572 & 2,596 & 1,543 & 1,635 & 355 & 255 & 7,223 \\
\hline
\end{tabular}




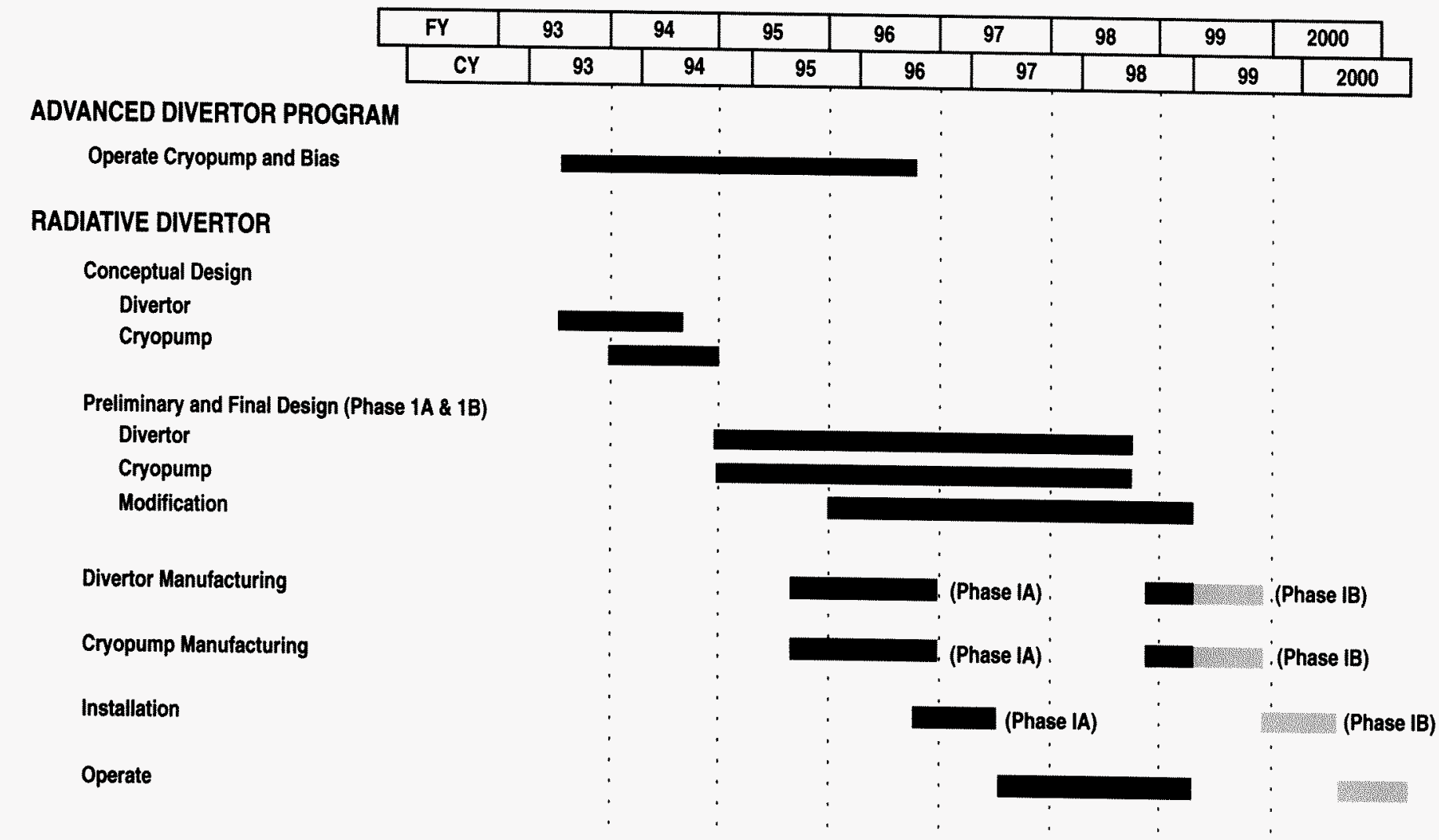

Fig. 6. Radiative divertor schedule. 


\section{LESSONS LEARNED}

During Phase 1A, despite having a well defined plan to qualify and select machining vendors, problems with vendor's capabilities and willingness to complete the job can arise. In selecting a machining vendor for the manufacturing of the water cooled panels, two vendors were selected to make prototypes based on their capabilities and past histories. The vendor who provided the best quality and on-time prototype panel was selected. The contract for the panels was let, but the vendor did not start the task until three weeks after receiving the job which was scheduled to be completed in fourteen weeks. The vendor was then unwilling to apply any more resources to make up the schedule and to resolve technical machining issues. Potentially, tracking more closely and being more aggressive early on may have helped in this situation, but it is not clear. To further aggravate this situation, the machining vendor upper management was switched half way through the task which caused further delays due to bringing the new management team up to speed.

In the ex-vessel support task, Element 3.0, an accountability issue arose during Phase 1A. The responsibility and authority of the task was not clearly defined between DIII-D operations and project staff. A clear and precise understanding at the beginning of the undertaking of the task by the responsible/assigned personnel would have alleviated the budget and schedule issue. This lesson learned as well as proper vendor selection and control were carried forth into Phase $1 \mathrm{~B}$ of the project.

In Phase 1B, the most critical aspect of the project was the manufacturing and assembly of large quantities of parts and components, and the dimensional control and tolerance management. Small deviations can arise at any point during the fabrication and assembly process and without proper control they can quickly grow and propagate. The experience with the inner RDP only reinforces this statement, dimensional and tolerance control is paramount. Specific examples during Phase 1B of the project; design, fabrication, and assembly illustrate the importance of this statement.

During the design phase of this portion of the project, early establishment of hard pre-existing reference points was crucial as was integration of the new geometry with pre-existing geometry. Validation and verification of the critical dimensions and interfaces, as well as avoiding interferences, with pre-existing hardware helped insure that the assembly would proceed accurately and quickly. The importance of references internal to the new geometry also became apparent. The inclusion of hard registration features in the design of the cryopump, for example, would have provided more accurate dimensional control during the assembly process and would have reduce the assembly time as well.

During fabrication, the qualification and capability of the vendor to produce the parts as designed, meeting the tolerances, as well as achieving the schedule milestones proved to have importance as demonstrated earlier during Phase 1A. The lesson learned in this case was to more critically question and screen more thoroughly potential vendors. More aggressive tracking may 
have improved the situation with certain vendors, but it may have just as easily made it worse. Another component of error that appeared during the fabrication phase was distortion caused by welding. Though it is difficult to accurately predict, it was found to be useful to have means to compensate for welding distortion.

The lesson learned during the assembly phase was that extra time and effort placed into careful tool design and pre-assembly more than made up for itself during final assembly inside the vacuum in both time and tolerance. Errors were identified and corrected in advance, dimensional control of the final assembly was both verified and controlled, the assembly procedure was fine tuned and validated, and the technicians gained valuable experience in handling and assembling components and systems. Development of a stud grinding tool saved a substantial amount technician labor and radiation exposure in the vessel.

\section{REFERENCES}

Project Information Sheet, DIII-D Radiative Divertor, July 28, 1993

Radiative Divertor Project Review, June 15-16, 1994

DIII-D Radiative Divertor Conceptual Design Review Report, August 17, 1994

Management Plan for the Radiative Divertor Project, October 1, 1994

RDP Project Authorizing Letter, November 17, 1994.

Diagnostic Plan for the Radiative Divertor, January, 1995.

Appendix B to the Management Plan, Plan for the Use of Vanadium Alloys in the Radiative Divertor, March 22, 1995.

Management Plan for the DIII-D Radiative Divertor Project , Revision One, July 22, 1996

[1] Management Plan for the DIII-D Radiative Divertor Project, Revision 1, July 1996.

[2] Management Plan for the DIII-D Radiative Divertor Project, Revised April 1999. 